\title{
Modeling Transit Trip Time Using Archived Bus Dispatch System Data
}

\author{
Robert L. Bertini ${ }^{1}$ and Ahmed M. El-Geneidy ${ }^{2}$
}

\begin{abstract}
Transit travel time and operating speed influence service attractiveness, operating cost, and system efficiency. The objective of this paper is to estimate the values of parameters that affect the total travel time for a particular bus route in Portland, Oregon. The Metropolitan Transportation District of Oregon (TriMet) provides transit service in the three-county Portland metropolitan area. TriMet has implemented a Bus Dispatch System (BDS) as a part of its overall service control and management system. This BDS provides a rich array of archived data that were used in this study to develop the trip time model for the route under study. This trip time model provides heightened understanding of the factors that affect the trip time on the route. The value of the model was revealed when sensitivity analyses were performed using data from the studied route. This analysis concluded that improvements can be readily achieved after understanding the factors that affect total trip time. Finally, some conclusions and recommendations are presented and suggestions for additional research are provided.
\end{abstract}

DOI: $10.1061 /(A S C E) 0733-947 X(2004) 130: 1(56)$

CE Database subject headings: Public transportation; Buses; Travel time; Transportation models.

\section{Introduction}

Transit travel time and operating speeds influence service attractiveness, operating cost, and system efficiency. If these data are available, they can also provide important descriptions of system performance for use in day-to-day operations management, route planning and scheduling, the transportation planning process (Levinson 1983), and continuing performance measurement and evaluation (NCHRP 1999). The objective of this paper is to estimate the values of parameters that affect the total travel time for a particular bus route in Portland, Oregon. This study will use very detailed stop-level data that are automatically collected and archived for each bus, route, and stop every day.

The Tri-County Metropolitan Transportation District of Oregon (TriMet) operates 97 bus routes and a 38-mile light rail line within the tricounty Portland metropolitan region. TriMet's bus lines carry approximately 200,000 trips per day, serving a total population of 1.3 million persons within an area of $1,530 \mathrm{sq} \mathrm{ki-}$ lometers (590 sq miles). The route chosen for this study was a 12.7-km (7.9-mile) segment of TriMet's Route 14 inbound (westbound), shown in Fig. 1. This is a heavily used inbound route that runs through southeast Portland toward downtown during the morning commute period. TriMet provides 105 scheduled trips per weekday on Route 14 with 64 stops. Scheduled trip times

\footnotetext{
${ }^{1}$ Assistant Professor, Dept. of Civil and Environmental Engineering, Portland State Univ., P.O. Box 751, Portland, OR 97207-0751. E-mail: bertini@pdx.edu

${ }^{2} \mathrm{PhD}$ Student, School of Urban Studies and Planning, Portland State Univ., P.O. Box 751, Portland, OR 97207-0751. E-mail: elgeneid@pdx.edu

Note. Discussion open until June 1, 2004. Separate discussions must be submitted for individual papers. To extend the closing date by one month, a written request must be filed with the ASCE Managing Editor. The manuscript for this paper was submitted for review and possible publication on May 16, 2002; approved on February 6, 2003. This paper is part of the Journal of Transportation Engineering, Vol. 130, No. 1, January 1, 2004. CASCE, ISSN 0733-947X/2004/1-56-67/\$18.00.
}

range between 40 and $45 \mathrm{~min}$ and scheduled headways range between 3 and $55 \mathrm{~min}$ (the mean headway is $11.4 \mathrm{~min}$ ). The analysis here concentrates on morning peak inbound service between SE 94th/Foster Ave. (location ID 1831) and the North Terminal, a layover and bus staging area near NW 4th/Hoyt St. (location ID 9573), near downtown Portland. In order to demonstrate the feasibility of this modeling approach, 14 inbound trips between 6:00 a.m. and 10:00 a.m. on Tuesday, February 1, 2001 were analyzed.

This paper describes how a trip time model was applied to the sample studied. It is shown that a trip time model can provide heightened understanding of the factors that affect transit trip time and lead to better operational decision-making and performance assessment. The value of the model will be revealed when sensitivity analyses are performed using data from the route studied.

\section{Data}

TriMet implemented a Bus Dispatch System (BDS) as a part of its overall operation and monitoring control system (Strathman et al. 1999, 2000, 2001). The main components of the BDS include the following:

- Automatic vehicle location (AVL) based upon differential global positioning system (GPS) technology, supplemented by dead reckoning sensors;

- Voice and data communication system using radio and cellular digital packet data (CDPD) networks;

- On-board computer and control head displaying schedule adherence information to operators and detection and reporting of schedule and route adherence to dispatchers;

- Automatic passenger counters (APCs) on front and rear doors of most vehicles (Kimpel 2001); and

- Computer-aided dispatch (CAD) center (Strathman et al. 2001).

The BDS reports detailed operating information in real time (every $90 \mathrm{~s}$ ) that enables the implementation of a variety of con- 


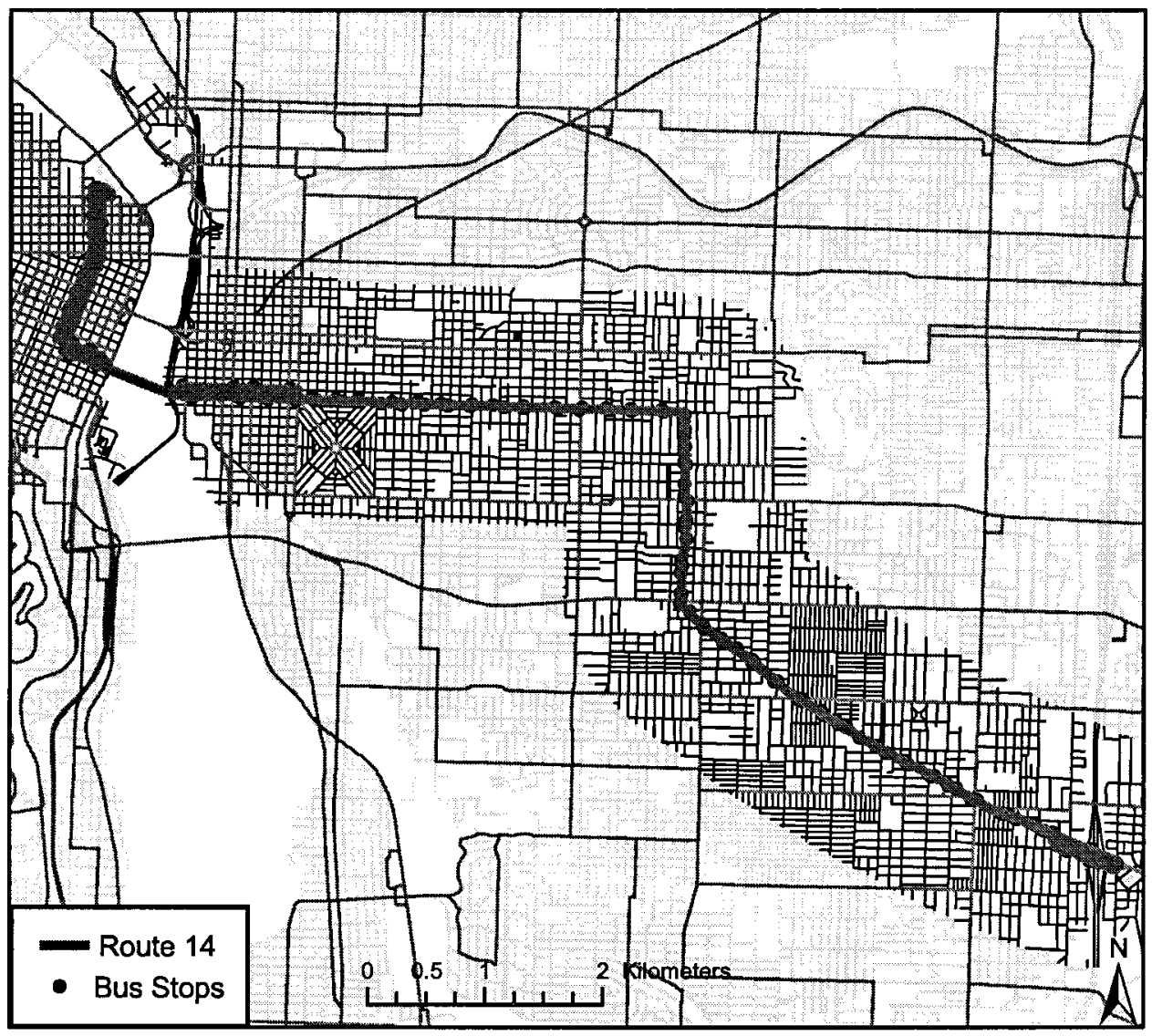

Projection: NAD 1983 StatePlane Oregon North FIPS 3601 Feet

Fig. 1. Route 14 map

trol actions by dispatchers and field supervisors. In addition, the BDS archives very detailed stop-level data from the bus during all trips that are postprocessed. Unique among U.S. transit systems, TriMet's BDS archives absolutely all of the data related to bus operations for every bus in the system every day. This includes the actual stop time (compared to the scheduled time), dwell time, and the number of boarding and alighting passengers at every stop. The BDS also logs data for every stop in the system, whether or not the bus stops to serve passengers. These archived data form a rich resource for planning and operational analysis as well as for research. Table 1 includes a sample list of archived
BDS data.

As shown in Table 1, the calendar date is indicated in the first field, and the vehicle number is displayed in the second field. In assigning trips, TriMet blocks the scheduled trips together in order to form what is known as a "train." Each train has a unique identification number, and is displayed as part of any row that is obtained from the BDS, in addition to the operator identification number and the route number. Each scheduled stop is geo-coded and has a unique identification number linked to a map database.

There are several fields related to the time the bus reaches the stop. The BDS system records the leave time and arrive time in

Table 1. Sample TriMet Bus Dispatch System Data

\begin{tabular}{|c|c|c|c|c|c|c|c|c|c|c|c|c|c|c|c|}
\hline $\begin{array}{l}\text { Date of } \\
\text { service }\end{array}$ & $\begin{array}{l}\text { Vehicle } \\
\text { number }\end{array}$ & Badge & Train & $\begin{array}{c}\text { Route } \\
\text { number }\end{array}$ & $\begin{array}{c}\text { Location } \\
\text { number }\end{array}$ & $\begin{array}{l}\text { Stop } \\
\text { time }\end{array}$ & $\begin{array}{l}\text { Arrive } \\
\text { time }\end{array}$ & Dwell & $\begin{array}{l}\text { Leave } \\
\text { time }\end{array}$ & Door & Lift & On & Off & $\begin{array}{l}\text { Pattern } \\
\text { distance }\end{array}$ & $\begin{array}{c}\text { Schedule } \\
\text { status }\end{array}$ \\
\hline 01FEB2000 & 2153 & 411 & 1405 & 14 & 1831 & $9: 25: 00$ & $9: 12: 50$ & 396 & $9: 25: 18$ & 1 & 0 & 2 & 0 & 49.91 & 5 \\
\hline 01FEB2000 & 2153 & 411 & 1405 & 14 & 1829 & $9: 26: 01$ & $9: 25: 34$ & 0 & $9: 25: 40$ & 0 & 0 & 0 & 0 & 335.19 & 2 \\
\hline 01FEB2000 & 2153 & 411 & 1405 & 14 & 1826 & $9: 26: 29$ & $9: 25: 46$ & 0 & $9: 25: 52$ & 0 & 0 & 0 & 0 & 489.95 & 2 \\
\hline 01FEB2000 & 2153 & 411 & 1405 & 14 & 1824 & $9: 27: 10$ & $9: 26: 12$ & 0 & $9: 26: 16$ & 0 & 0 & 0 & 0 & 762.22 & 2 \\
\hline 01FEB2000 & 2153 & 411 & 1405 & 14 & 1818 & $9: 28: 00$ & $9: 26: 36$ & 14 & $9: 27: 44$ & 1 & 0 & 0 & 1 & $1,066.38$ & 4 \\
\hline 01FEB2000 & 2153 & 411 & 1405 & 14 & 1817 & $9: 28: 35$ & $9: 27: 54$ & 7 & $9: 28: 22$ & 1 & 0 & 1 & 0 & $1,253.87$ & 2 \\
\hline 01FEB2000 & 2153 & 411 & 1405 & 14 & 1815 & $9: 29: 12$ & $9: 28: 26$ & 0 & $9: 28: 38$ & 0 & 0 & 0 & 0 & $1,395.66$ & 2 \\
\hline 01FEB2000 & 2153 & 411 & 1405 & 14 & 1813 & 9:30:01 & $9: 28: 52$ & 0 & $9: 28: 58$ & 0 & 0 & 0 & 0 & $1,732.05$ & 2 \\
\hline 01FEB2000 & 2153 & 411 & 1405 & 14 & 1811 & $9: 30: 48$ & $9: 29: 20$ & 5 & $9: 29: 30$ & 1 & 0 & 1 & 0 & $1,972.35$ & 2 \\
\hline 01FEB2000 & 2153 & 411 & 1405 & 14 & 1811 & $9: 30: 48$ & $9: 29: 30$ & 0 & $9: 29: 36$ & 0 & 0 & 0 & 0 & $2,018.18$ & 1 \\
\hline 01FEB2000 & 2153 & 411 & 1405 & 14 & 1807 & $9: 31: 40$ & $9: 30: 02$ & 6 & $9: 30: 14$ & 1 & 0 & 2 & 0 & $2,280.17$ & 2 \\
\hline 01FEB2000 & 2153 & 411 & 1405 & 14 & 1807 & $9: 31: 40$ & $9: 30: 14$ & 0 & 9:30:18 & 0 & 0 & 0 & 0 & $2,319.32$ & 1 \\
\hline
\end{tabular}



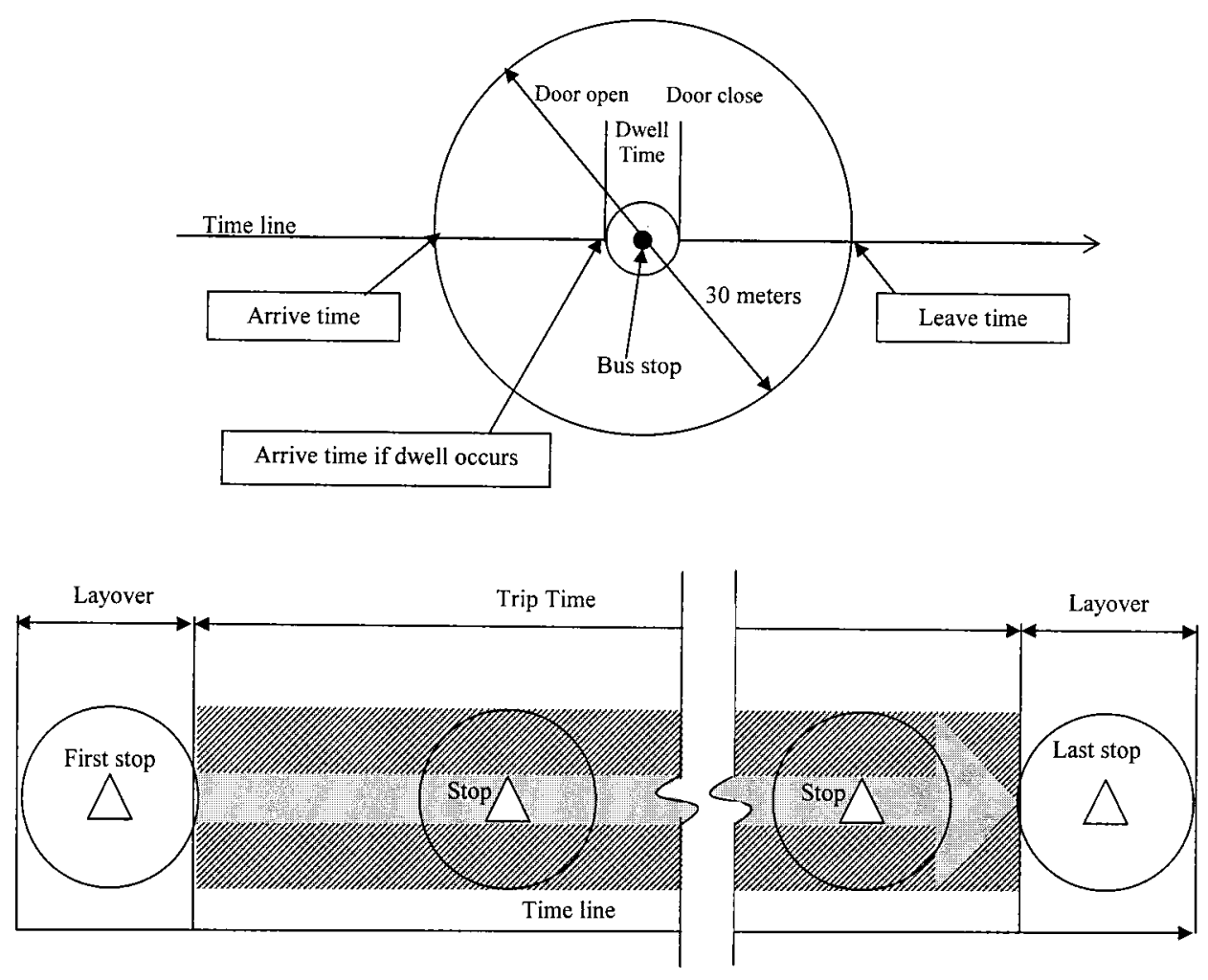

Fig. 2. Stop circle and time interval studied

seconds past midnight. Each geo-coded stop has a predefined 30$\mathrm{m}$ (98-ft) stop circle surrounding the stop. As shown in Fig. 2, the arrive time is recorded as the time the bus enters the stop circle while the leave time is the time the bus departs the stop circle. The arrive time and the leave time are recorded at all stops even if the bus does not stop to serve passengers. When there is an unscheduled stop, an artificial 30-m circle is created around the stop. If the door opens to serve passengers at either a scheduled or unscheduled stop, a $d w e l l$ is recorded, and the arrive time is overwritten by the time the door opens. Dwell time (in seconds) is recorded in another field called dwell, which is recorded as the total time that the door remains open. Thus, the time that the door closes is also known after adding the value of the dwell time to the arrive time.

When passenger activity occurs, the APCs count the total number of boarding and alighting passengers which are then recorded separately in two fields. The APCs are installed at both front and rear doors, and use infrared beams to detect passenger movement. The APCs are only activated if the door opens. The use of a lift to assist passengers with disabilities is indicated in a separate field in the BDS database. Different types of stops occur during a bus trip. For example, the first and last stops, the schedule time points, primary stops, pseudostops (stops coded for informational purposes only), and unscheduled stops have unique identification numbers that are stored in the schedule status field. Each trip includes layover time at the beginning and end. This layover time may include time when the doors are open or closed while the bus is waiting to start a new trip.

As shown in Fig. 2, the development of the Route 14 trip time model began with the departure time from the first stop and ended with the arrival time at the last stop (excluding layovers at the beginning and end of each trip). Modeling the nonlayover travel time (hatched area in Fig. 2) will be the area of interest in this study.

\section{Analysis}

\section{General Analysis}

Key trip-level statistics were extracted from the BDS database for Route 14. The average trip time for the 14 trips studied was 43.3 min and standard deviation (SD) for the trip time was $2.7 \mathrm{~min}$. Fig. 3 is a time-space diagram of the 14 consecutive trips (where the $x$ axis is time, and the $y$ axis is cumulative distance), plotted so that the slope of each trajectory is the average speed of a bus at a particular point in time and space. Fig. 3 shows how the buses' speed varies over time (scheduled times are not shown for clarity). Analyzing one of these trajectories in depth will help to understand how the speed varies with the distance and the factors that affect trip time.

The first trip, labeled train 1410 in Fig. 3, left the stop circle at SE Foster/94th at 5:24:30 a.m. and arrived at NW 4th and Hoyt at 6:05:42 a.m. The bus passed 64 stops, stopped a total of 35 times (with door openings recorded), and served 44 boarding and 48 alighting passengers, comprising a total dwell time of $483 \mathrm{~s}$ (8.02 min). The average speed of this trip (including dwell time) was $16.9 \mathrm{~km} / \mathrm{h}$ (10.5 miles/h). Within the stop circles the average speed was $10.3 \mathrm{~km} / \mathrm{h}(6.4 \mathrm{miles} / \mathrm{h})$, and outside of the stop circles, when the bus was potentially traveling with regular traffic, the average speed was $40.4 \mathrm{~km} / \mathrm{h}$ (25.1 miles/h). Between kilometers 10 and 11, the route crosses the Willamette River using the Hawthorne Bridge (a 1910 vertical lift bridge). As shown in Fig. 3, the bus speed as it crosses the bridge was nearly constant for all 14 trips in the analysis.

Fig. 4 shows the distribution of the trip service time for all trips. As is shown, $16 \%$ of the cumulative service time was spent stopped with doors open (defined as a dwell), with a total of $3 \%$ of the time was spent as dwells at layover stops and $13 \%$ as dwells at all other stops. During the remaining $84 \%$ of the time, 


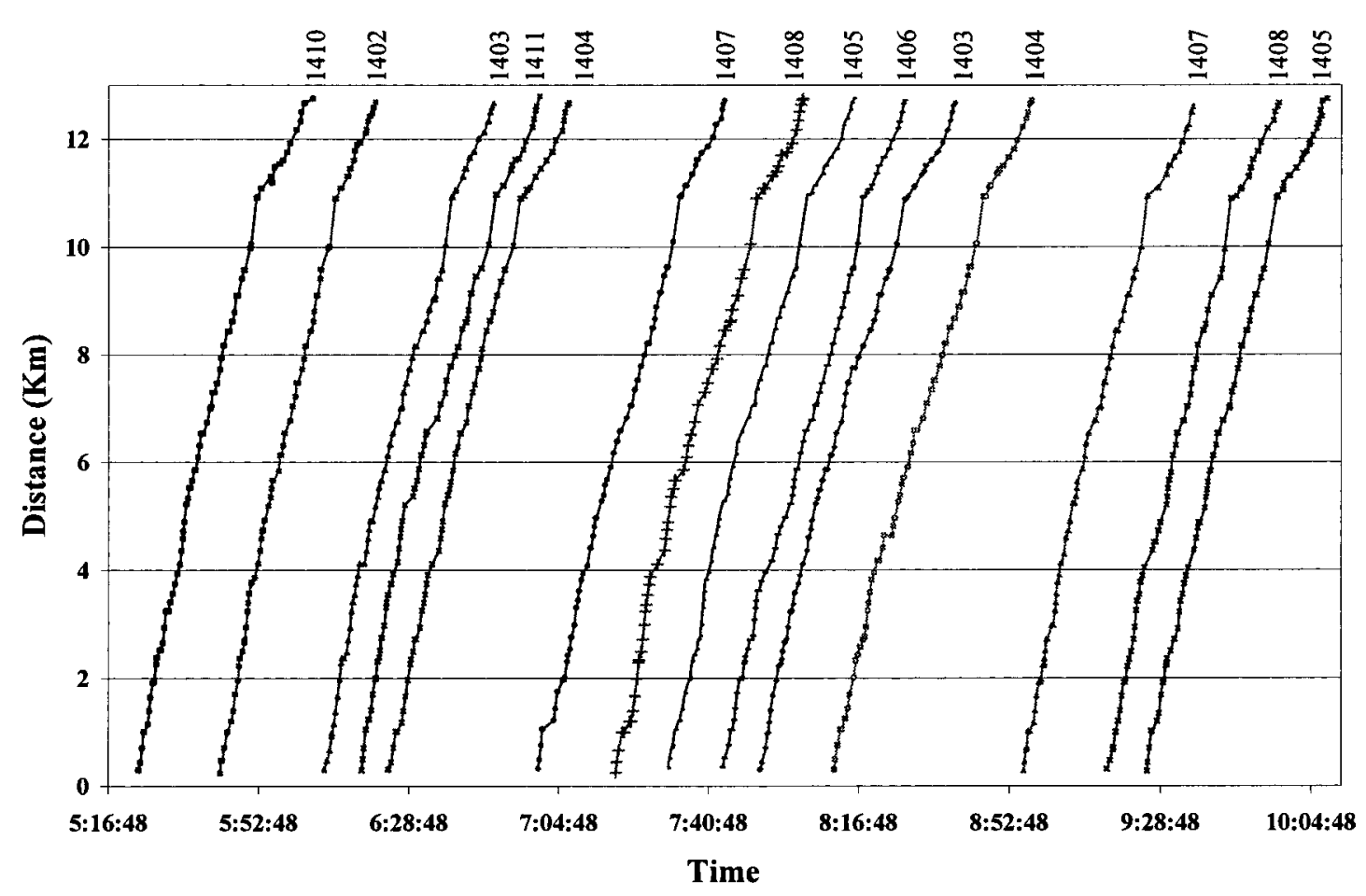

Fig. 3. Cumulative distances versus time for 14 trips

the buses were either stopped, accelerating, decelerating, or moving with traffic. Fig. 4 also shows that a total of $19 \%$ of the service time was spent within stop circles at layovers-3\% with doors open and $16 \%$ with doors closed. During a portion of the latter time it is possible that the buses were either stopped and/or moving.

During the remaining $68 \%$ of total service time, buses were outside layover stop circles and had their doors closed. A total of $12 \%$ of the service time was spent passing through the stop circles for locations of stops where buses did not stop to serve passengers. A total of $30 \%$ of the service time was spent traveling with normal traffic and within stop circles associated with dwells but before the door was opened (including deceleration and time lost due to stopping). A total of $26 \%$ of the service time for the sample trips was spent within stop circles associated with dwells, but after the doors were closed (including time lost and acceleration). This analysis reveals the significance of the layovers and the power of the BDS data for understanding the components of transit service time.

To understand the relationship between actual service and scheduled service, Fig. 5 shows a comparison between scheduled stop times and actual stop times for one trip (train 1405) that left the origin at 9:25 a.m. (the $x$ axis is time and the $y$ axis is cumulative distance traveled). As shown in Fig. 5, the bus was running on schedule during the first 54 stops; the bus arrived on average $22 \mathrm{~s}$ early at all of these stops. The bus experienced a notable delay at a location where six passengers boarded the bus and three passengers alighted at the same stop (SW Main and 3rd in down-

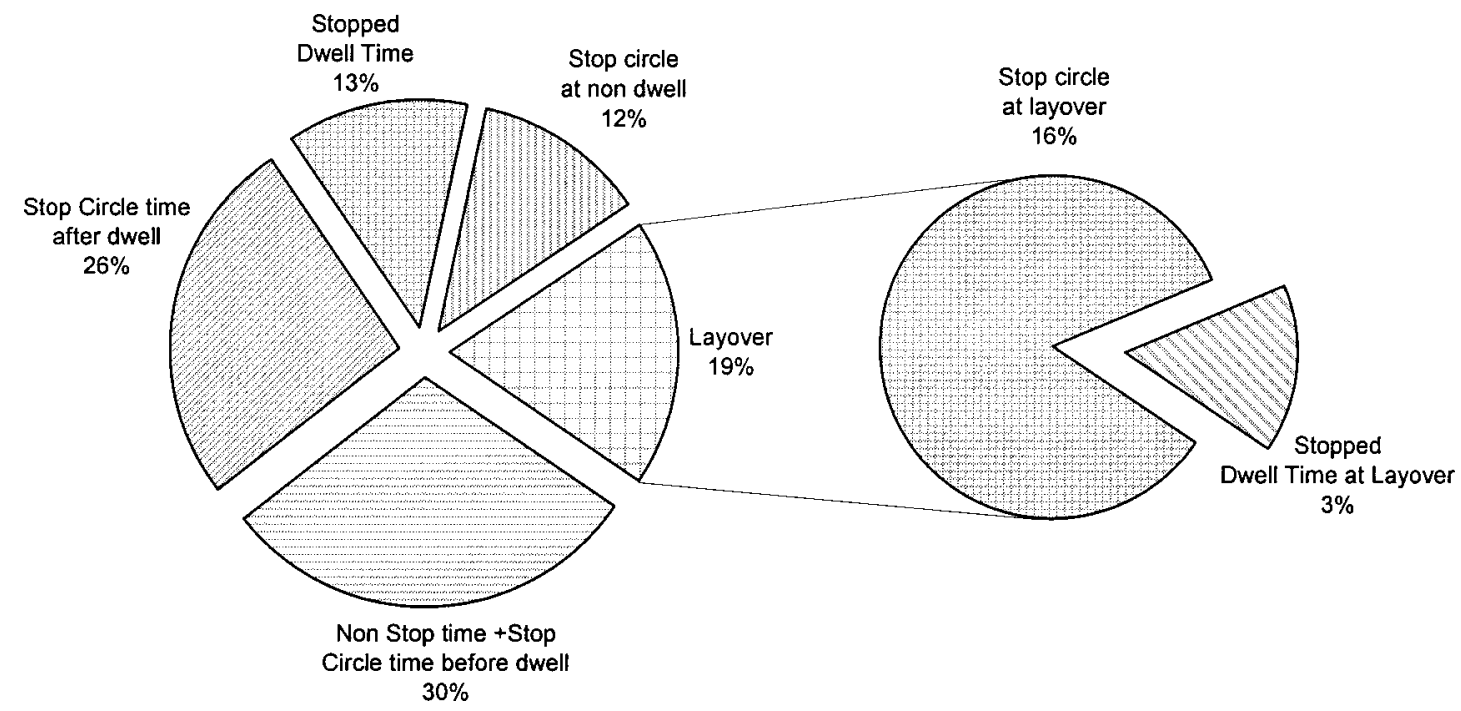

Fig. 4. Time distribution for all trips 


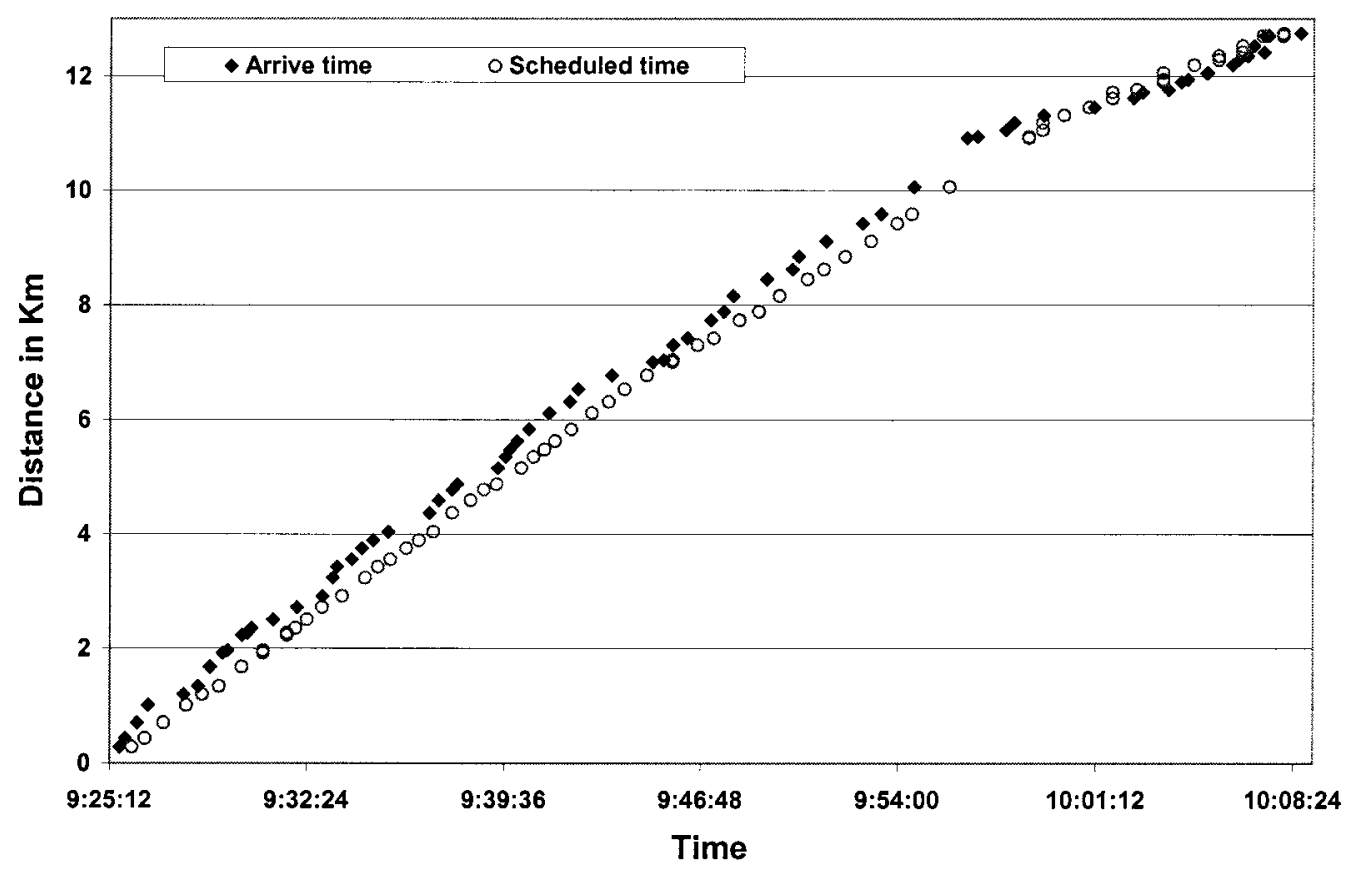

Fig. 5. Actual service time compared with scheduled service (train 1405)

town Portland). Delays can result from a surge in passenger demand, which means that the trip time can vary according to the number of boarding and alighting passengers. The trip time was also likely impacted by traffic control, traffic congestion, and individual operator characteristics (Kimpel 2001).

\section{Dwell Time Analysis}

Dwell time is an important parameter that affects transit service quality (Levinson 1983). Fig. 6 is a histogram of dwell time for all 459 stops with passenger activity that were recorded during the sample trips. The mean dwell time was $12.4 \mathrm{~s}$ and the SD was $9.2 \mathrm{~s}(n=459)$. The total number of passengers boarding and alighting at all stops was 1,394 passengers, an average movement of 3 passengers for each stop.

Dwell time is determined mainly by passenger activity at each stop (Chien et al. 2000). In order to further understand the distribution of passenger activity over time, Fig. 7 shows the relation- ship between the total dwell time and the time of day for the 14 trips studied. Fig. 7 shows an increase in total dwell time during the peak period and a drop in total dwell time during the off-peak period. Also, when a lift operation occurs, the dwell time is altered dramatically. The lift was used once during the 14 trips and the dwell time at that stop was $102 \mathrm{~s}$ to serve one passenger.

Passenger activity is composed of one of three actions: (1) passenger(s) alighting only; (2) passenger(s) boarding only; and (3) passengers boarding and alighting at the same time (TriMet passengers board through the front door and alight through either the front or rear door). Fig. 8 shows the different types of stops and the percentage of each action for the 459 dwells. Fig. 8 shows that 255 stops included only passengers boarding (56\%), 111 stops included only passengers alighting (24\%), and 68 stops included both $(15 \%)$. The remaining 24 dwells (stops where doors opened) were not accompanied by any recorded passenger movement $(5 \%)$. This subdivision will facilitate a clearer understanding

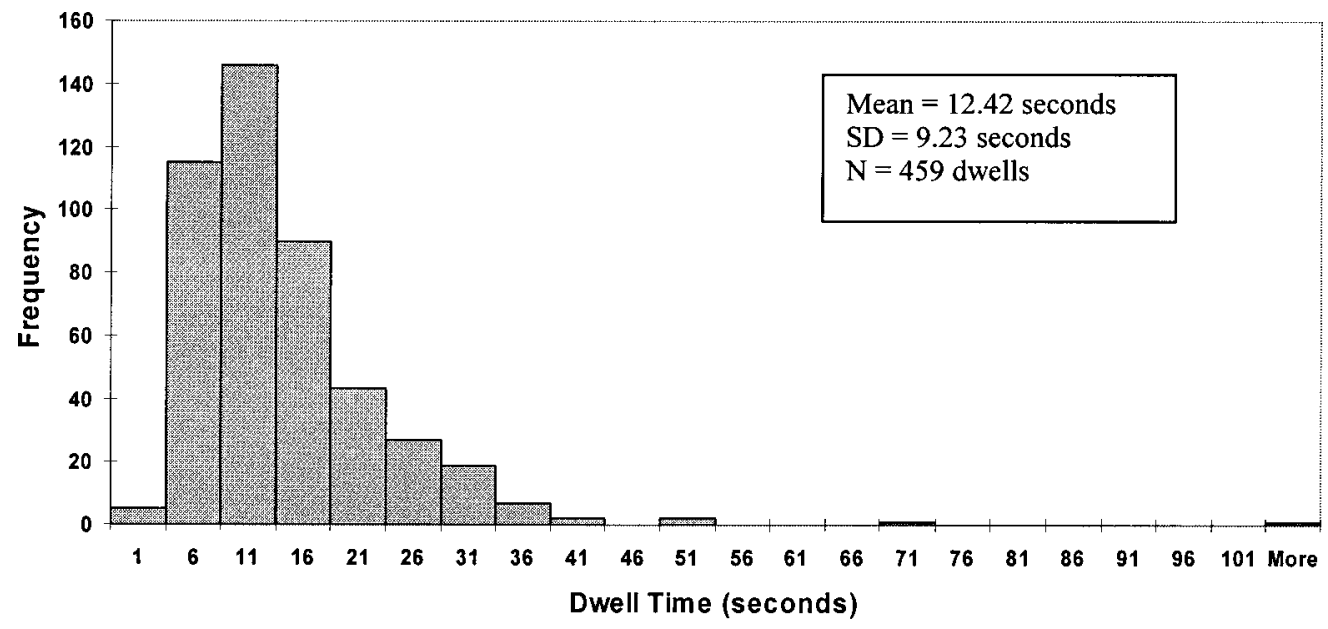

Fig. 6. Dwell time histogram for 14 trips 


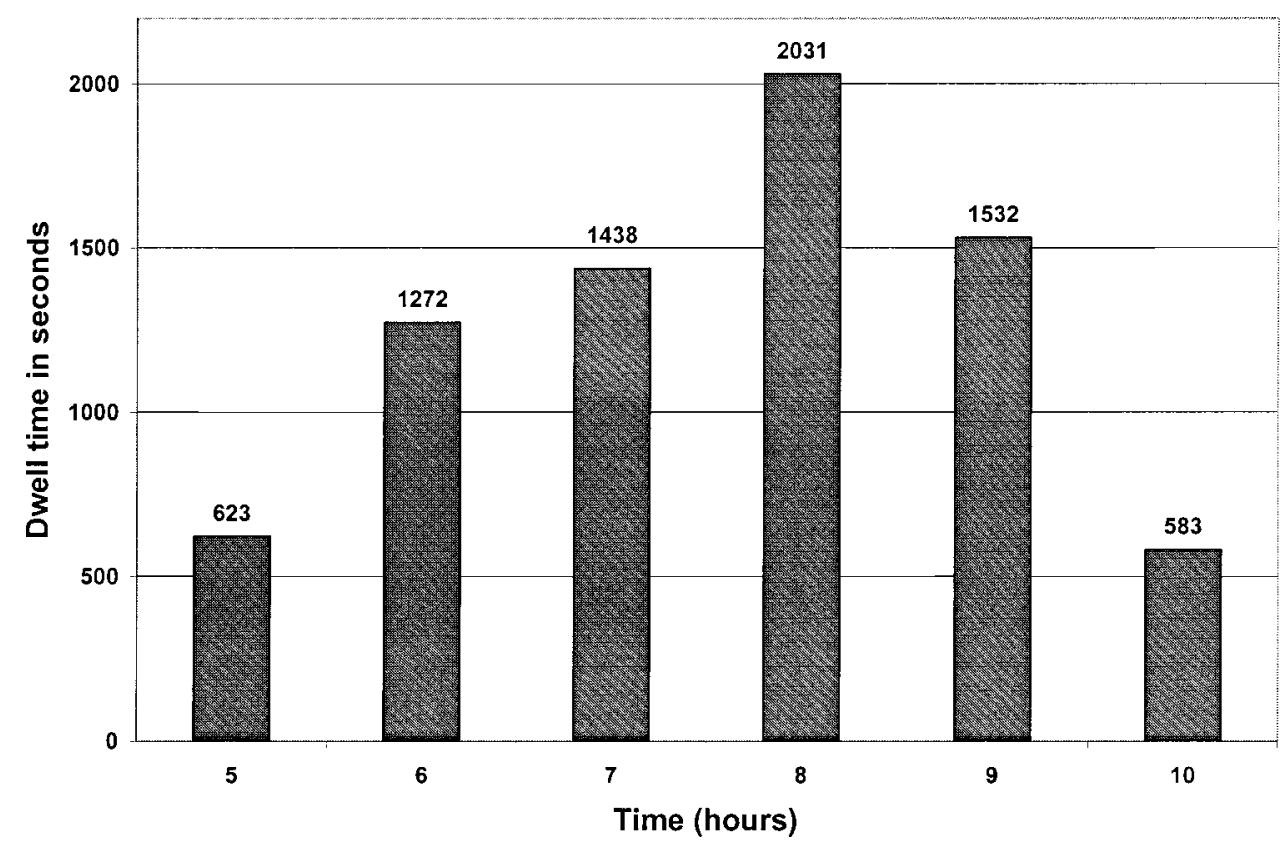

Fig. 7. Total dwell time (h)

of the mean time required for a passenger to board or alight in the absence of other activity. In fact, the mean time for a passenger to alight was $2.4 \mathrm{~s}$ ( $n=111$ dwells and 480 alighting passengers). The mean time for a passenger to board (no lifts were included) was $6.0 \mathrm{~s}$ ( $n=255$ dwells and 499 boarding passengers). The mean time required when there are both alighting and boarding passengers was $3.8 \mathrm{~s}$ ( $n=68$ dwells with 180 alighting passengers and 169 boarding passengers).

\section{Passenger Movement Analysis}

Passenger movement drives transit service yet clearly affects the trip time (Levinson 1983). As noted in the example above, the bus (train 1405) was delayed most due to the activity of nine passengers at one stop. It is clear that a transit agency would like to maximize the efficiency of the boarding and alighting process. Fig. 9 is a histogram showing the number of passengers alighting the buses on the 14 studied trips and Fig. 10 is a histogram showing the number of boarding passengers. The total number of pas-

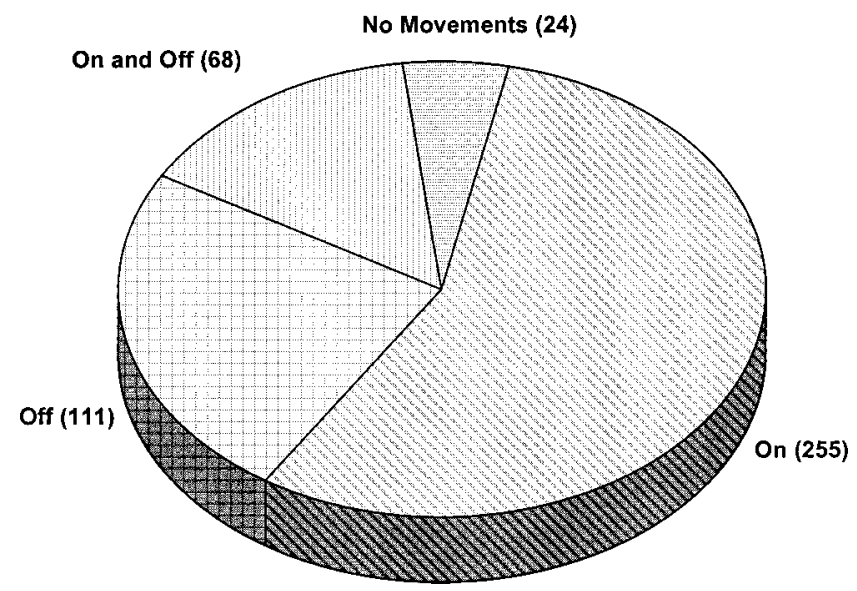

Fig. 8. Different types of dwells sengers boarding the buses was 706 passengers while the total number of passengers alighting was 688 .

Fig. 11 shows the relationship between dwell time and total passenger activity. Notice that high passenger movement is not necessarily associated with a long dwell time. This indicates that longer dwell times are not necessarily correlated with high volumes of passenger activity. Note that "dwell" is the total time that the door is open, so there could be times when the door remains open but no passengers are served. In addition, some of the short dwells were accompanied by large passenger movements.

\section{Trip Time Analysis}

Next we consider that TriMet Route 14 serves passengers at numerous bus stops that are far enough apart such that a bus can reach its cruising speed between any two stops. To illustrate this, Fig. 12 shows a partial bus trajectory on a time-space plane. As is shown, a trip can be partitioned into two components: the time that a bus is stopped (horizontal lines) and the time that a bus is traveling between stops (sloping lines). We thus assume that the average time lost at some $i$ th stop, if a bus stops, is a constant, $a$, plus the time required to serve boarding and alighting passengers at that stop. This added dwell time is some multiple $b$ of the number of alighting passengers $N_{a i}$ at the $i$ th stop, $b N_{a i}$, plus a multiple $c$ of the number of boarding passengers $N_{b i}$ at stop $i$, $c N_{b i}$. We assume $a, b$, and $c$ are independent of $i$ (Newell 1995). From this we conclude that the average time $T$ required for a bus to traverse the route has the form

$$
T(\mathrm{~s})=T_{0}+a N_{d}+b N_{a}+c N_{b}
$$

where $T_{0}=$ average nonstop trip time of a bus; $N_{d}=$ number of times a bus stops (dwells); $N_{a}=$ total number of passengers alighting a bus; and $N_{b}=$ total number of passengers boarding a bus.

Using the form shown in Eq. (1) and the archived TriMet BDS data, the average trip time for the sample trips can be modeled. The first step is to plot the dwell time versus the total number of passengers boarding and alighting at each stop as shown in Fig. 


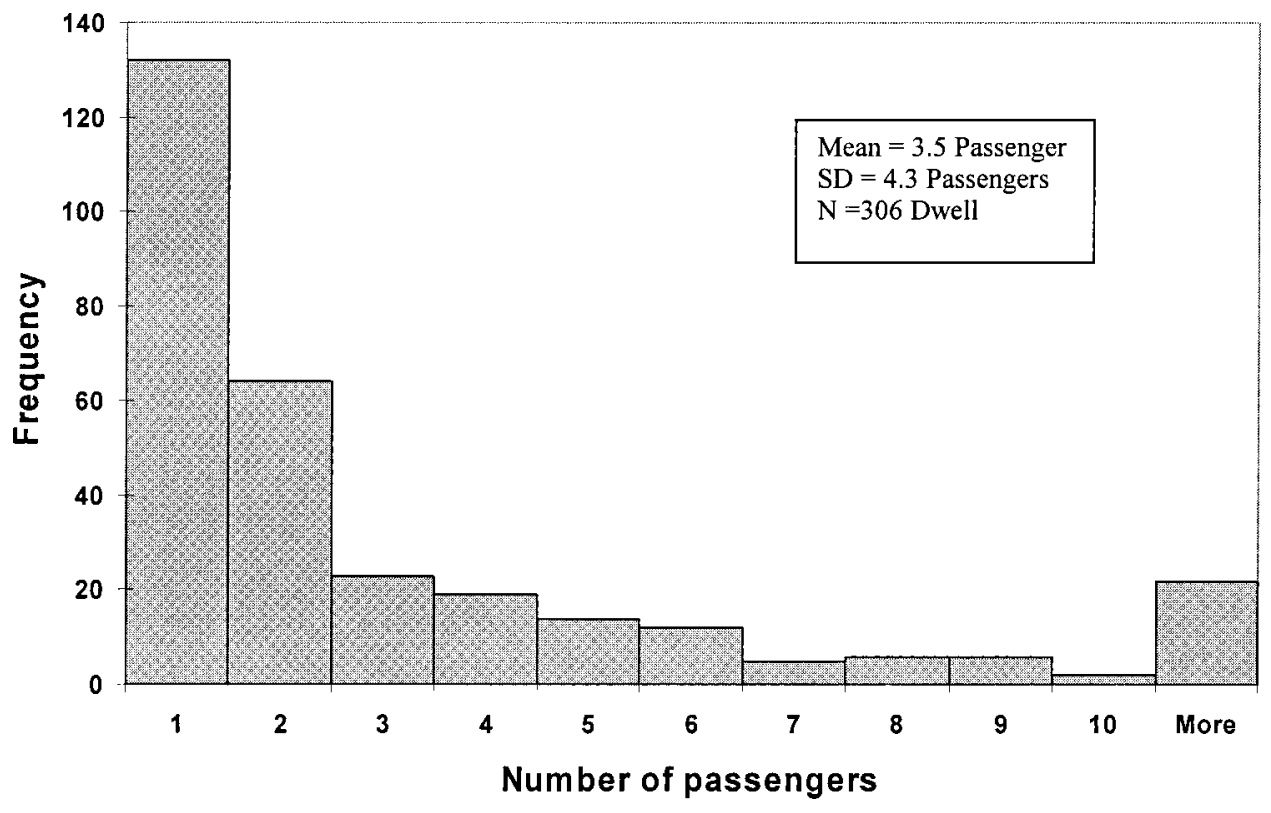

Fig. 9. Alighting passengers

13. The time lost due merely to stopping is clearly visible as the $y$ intercept. Using simple linear regression, the following initial best-fit model was developed:

$$
\text { dwell time }(\mathrm{s})=9.5+1.2\left(N_{a}+N_{b}\right)
$$

The regression output revealed that $R^{2}=0.15$, with parameters significant at the $95 \%$ level. This indicates that each stop that served passengers includes approximately $9.5 \mathrm{~s}$ of time resulting merely from stopping, and an additional $1.2 \mathrm{~s}$ to serve each boarding or alighting passenger. Due to a poor fit, this model was discarded in favor of another model estimated using separate coefficients for the number of boarding and alighting passengers. The resulting relationship is

$$
\text { dwell time }(\mathrm{s})=5.8+0.85 N_{a}+3.6 N_{b}
$$

The second model indicates that approximately $5.8 \mathrm{~s}$ of time lost is attributable to each stop accompanied by a door opening regardless of the number of passengers boarding and/or alighting. An additional $0.85 \mathrm{~s}$ is consumed for each alighting passenger (through both doors) and approximately $3.6 \mathrm{~s}$ is consumed by each passenger boarding through the front door. This appears to be a better estimate of dwell time, since it accounts for the effects of boarding and alighting passengers separately. This regression output revealed $R^{2}=0.47$, with parameters significant at the $95 \%$ level. Note that the analysis was performed after removing several outliers from the BDS data.

In order to verify the coefficients in Eq. (3), separate analyses for stops with only boarding passengers or only alighting passengers were conducted. The following dwell time model was

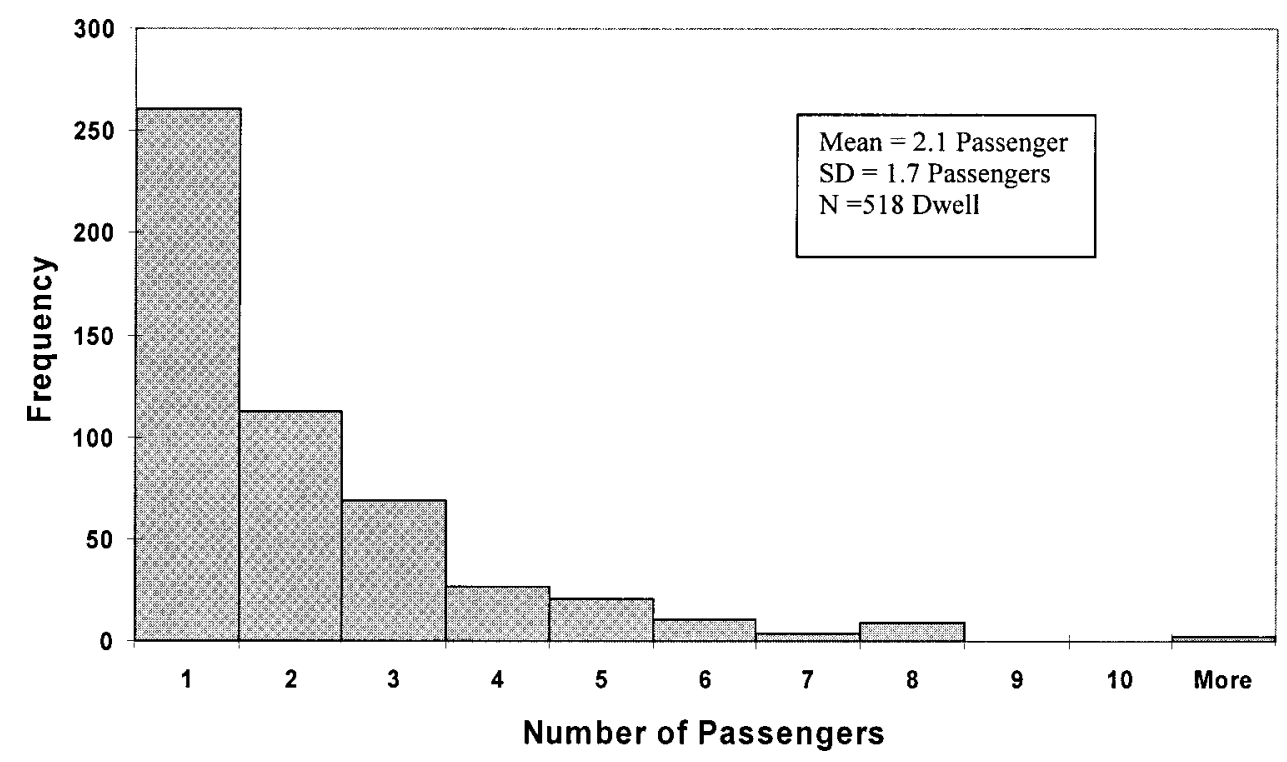

Fig. 10. Boarding passengers 


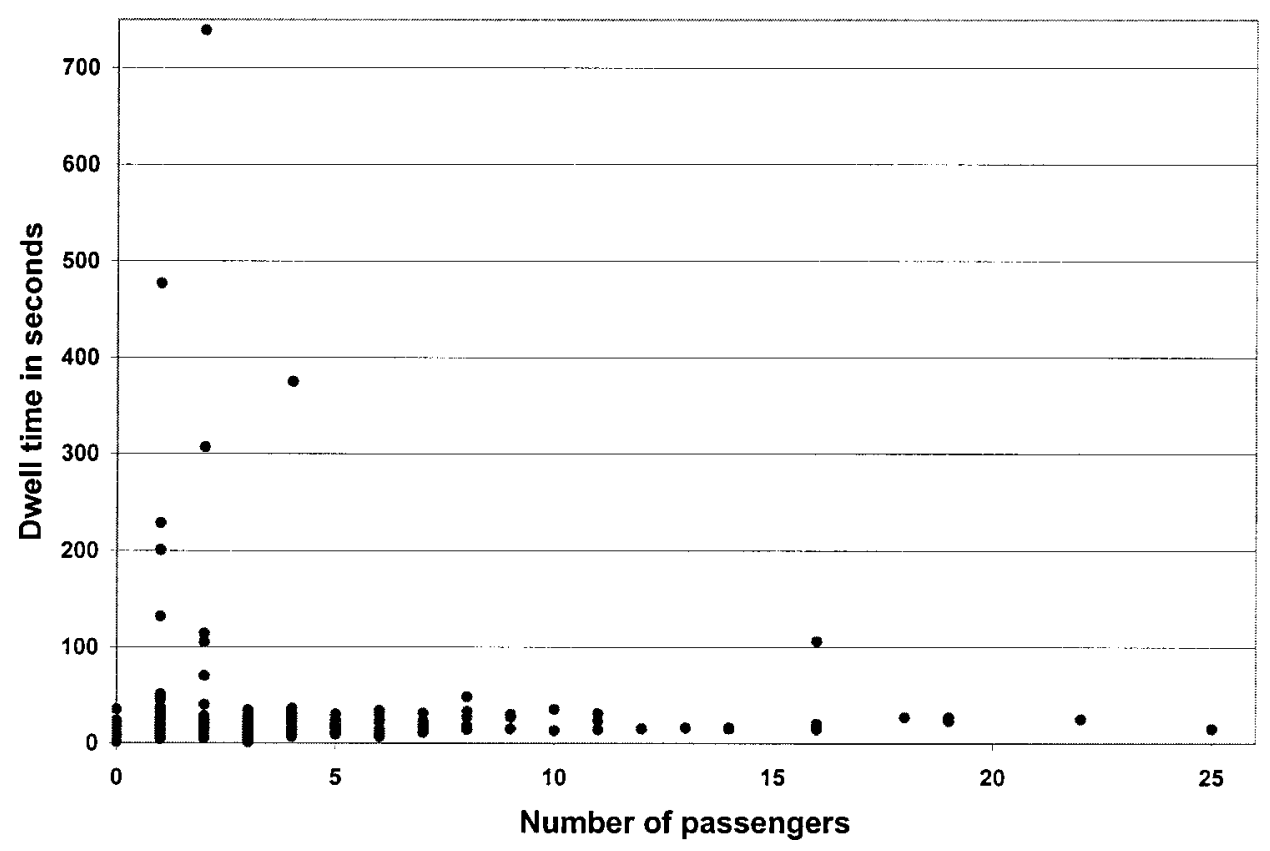

Fig. 11. Dwell time and total passenger movement

developed for the dwell time for boarding $\left(n=255, R^{2}=0.45\right.$, parameters significant at the $95 \%$ level):

$$
\text { dwell time }(\mathrm{s})=5.0+3.5 N_{b}
$$

The results indicate $5.0 \mathrm{~s}$ of time lost at stops with only boarding passengers and a mean boarding time of $3.5 \mathrm{~s}$. This is consistent with the values of the parameters revealed by Eq. (3). The following dwell time model was developed for dwells when only alighting passengers were recorded $\left(n=111, R^{2}=0.49\right.$, parameters significant at the $95 \%$ level):

$$
\text { dwell time }(s)=7.6+0.64 N_{a}
$$

The results indicate $7.6 \mathrm{~s}$ of time lost at each stop that included only alighting passengers and a mean alighting time of less than 1 s. These findings are also reasonably consistent with the values of the parameters in Eq. (3).

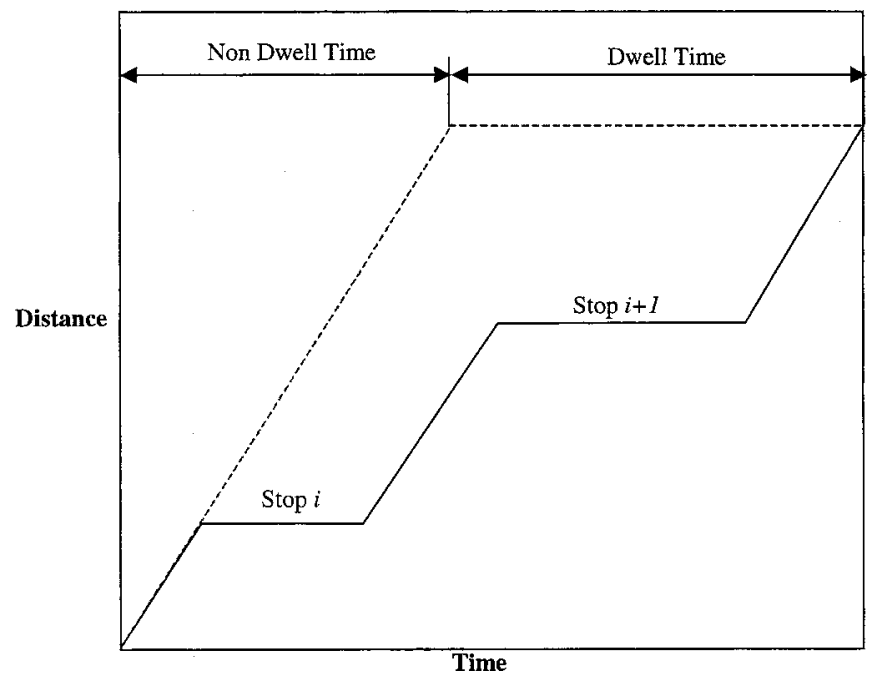

Fig. 12. Trip time analysis
The next step was to investigate the relationship between interstop trip time and distance. The difference between the time the door was closed at stop $i-1$ and the time the door was opened at stop $i$ was used to represent the trip time between the two stops. A plot of the actual archived data is shown in Fig. 14. Again, simple linear regression was used to estimate a linear relationship between trip time in seconds and distance in kilometers. The model output confirms the graphical representation as follows:

$$
\text { nonstop trip time }(\mathrm{s})=20.2+118.5 \mathrm{D}
$$

The results indicate that approximately $20.2 \mathrm{~s}$ of time lost is attributable to the deceleration and acceleration required for stopping. In addition, it is shown that each kilometer ( 0.62 mile) of travel is associated with $118.5 \mathrm{~s}$ of trip time between stops. The regression output revealed $R^{2}$ of 0.65 , with parameters significant at the $95 \%$ level.

Now, combining the results of the above analyses, it is possible to develop the final trip time model desired [Eq. (1)]. Coefficients $b$ and $c$ are clearly available from Eq. (3), and are 0.85 and 3.6, respectively. Constant $a$ is the sum of the two constants in Eqs. (3) and (6), $5.8+20.2=26.0 \mathrm{~s}$. This represents the sum of the time lost due merely to stopping (and is not related to passenger loading and unloading) and the time lost due to acceleration and deceleration. Finally, $T_{0}$, the average nonstop trip time is simply the product of the average pace, $118.5 \mathrm{~s} / \mathrm{km}$ times the length of the route, $12.7 \mathrm{~km}$ (7.9 miles), giving a total value of the average nonstop trip time of $1,506.6 \mathrm{~s}$.

This analysis provides the following equation for the average time $T$ required for TriMet Route 14 to traverse the 12.7- $\mathrm{km}$ (7.9mile) segment between 6:00 a.m. and 10:00 a.m.:

$$
T=26.0 N_{d}+0.85 N_{a}+3.6 N_{b}+1506.6
$$

where $T=$ trip time; $N_{d}=$ number of dwells; $N_{a}=$ total number of passengers alighting the bus; and $N_{b}=$ total number of passengers boarding the bus.

This formula reveals that the nonstop trip time would be $1506.6 \mathrm{~s}$, approximately $25.1 \mathrm{~min}$ at $30.3 \mathrm{~km} / \mathrm{h}(18.8 \mathrm{mi} / \mathrm{h})$. Each 


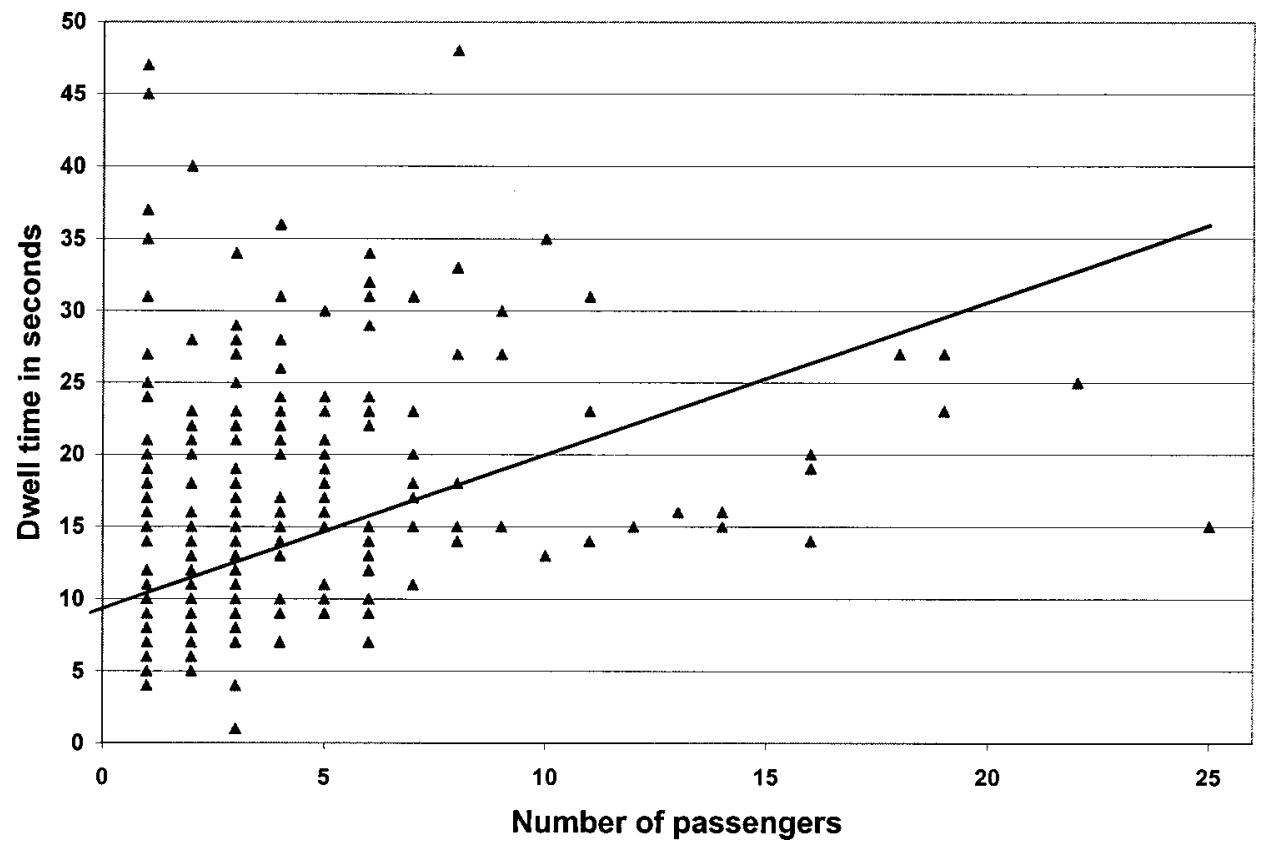

Fig. 13. Number of passengers and dwell time

stop adds $26.0 \mathrm{~s}$ to the trip, each alighting passenger adds $0.85 \mathrm{~s}$, and each boarding passenger adds approximately $3.6 \mathrm{~s}$. Note that this formula takes into consideration that passengers alighting the bus use both doors.

The trip time model described in Eq. (7) was tested using the source data for the sample trips. Comparisons between the predicted trip times (based on the three parameters) and actual trip times are plotted in Fig. 15. The mean error for the 14 trips was 6.7\%. Fig. 15 shows each point (actual versus predicted) as well as error bars around the actual values showing $\pm 5 \%$. Considering the relatively small sample size, this range of error seems reasonable. Future research will allow testing of the model using data from considerably more trips.

\section{Sensitivity Analysis}

Now that a trip time model has been proposed, it is possible to examine the impact of the input parameters on the cost of providing transit service. The route length is about 1,271 $\mathrm{m}(41,710 \mathrm{ft})$

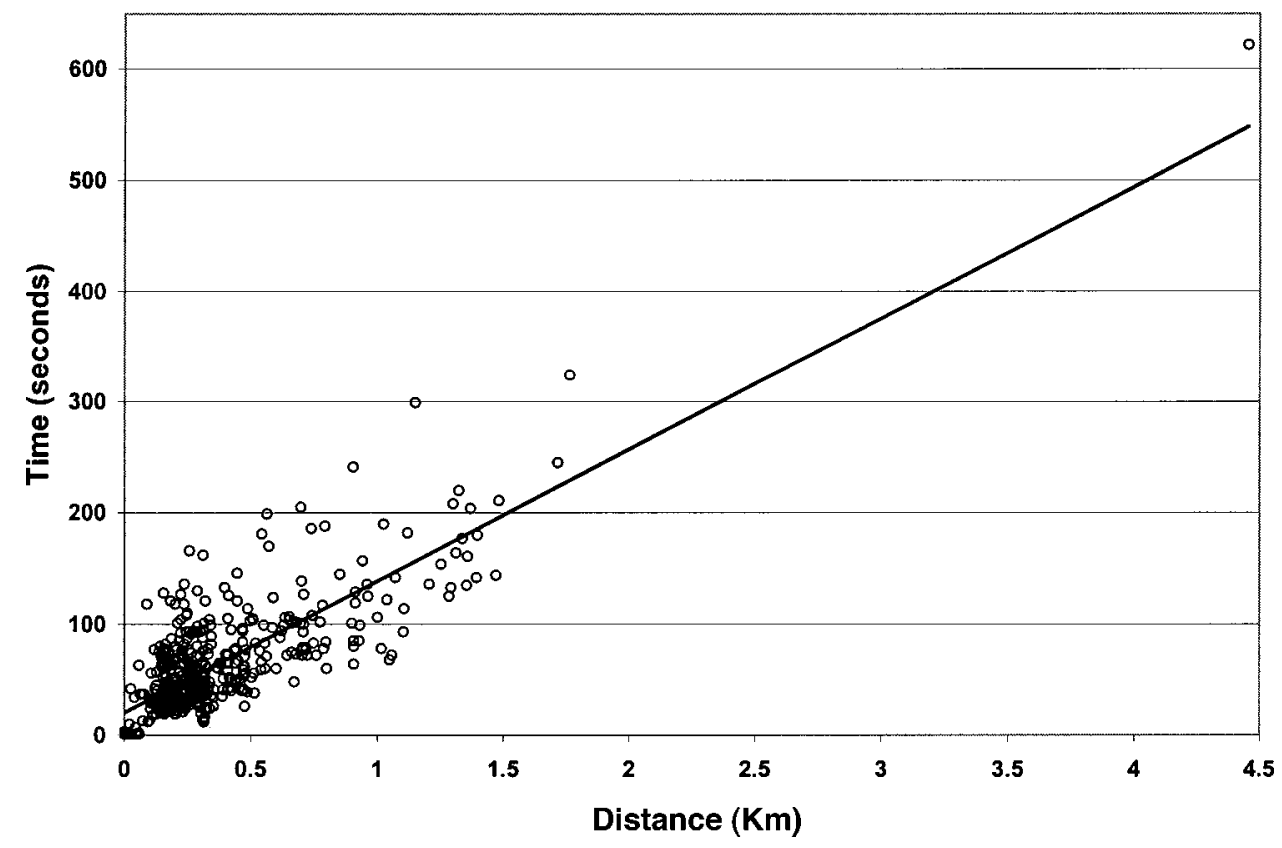

Fig. 14. Nondwell time versus distance 


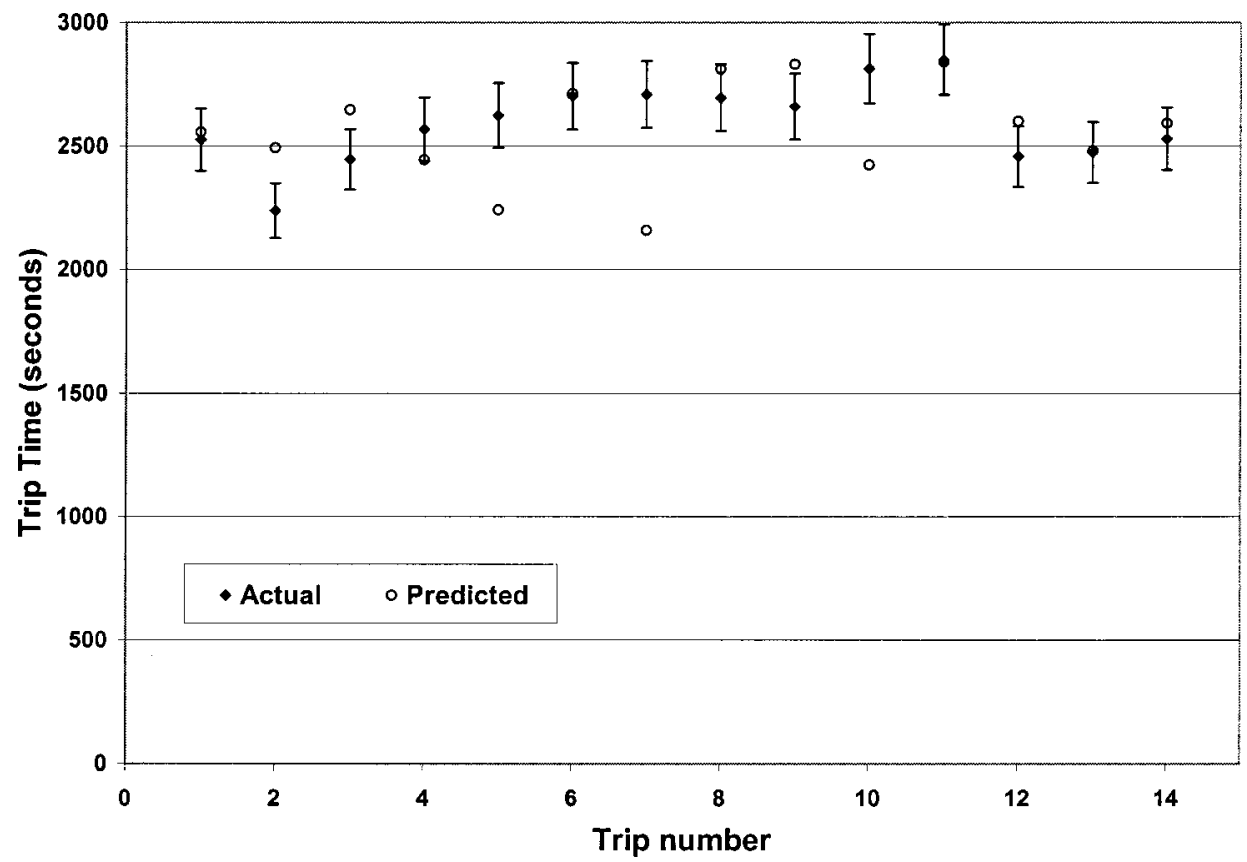

Fig. 15. Actual and predicted trip times

with an average distance between stops of $204 \mathrm{~m}(670 \mathrm{ft})$. In general, there is a trade-off between providing too many transit stops (that maximizes accessibility, but also results in longer trip times) and not enough stops (that reduces accessibility and results in shorter trip time). It is very difficult to develop optimal transit stop locations, but it is recognized that over time stops may need to be moved or consolidated due to shifts in demography and development changes. Consolidating stops is one operational strategy that can be used to reduce the trip time and affect operating speed and headways (Saka 2001). However, this type of action increases the distance that passengers must walk to access the transit system and may disrupt historical travel patterns. If we consider a hypothetical stop consolidation program that would increase the mean distance between scheduled stops to $305 \mathrm{~m}$ $(1,000 \mathrm{ft}), 10$ stops would need to be eliminated from the route (other stops would be relocated in order to balance the spacing of stops). According to the trip time model, the trip time of a single vehicle would be reduced by approximately 260 s $(26.0$ s/stop $\times 10$ stops), or 4.3 min. Between 6:00 and 10:00 a.m., TriMet operates 14 trips in the inbound direction of Route 14, so the total saving of time during this 4-h period due to stop consolidation would be about $60 \mathrm{~min}$. TriMet provides 105 trips per day in the inbound direction on Route 14 so the savings could be up to $452 \mathrm{~min}(7.5 \mathrm{~h})$ per day of service time. Even without performing

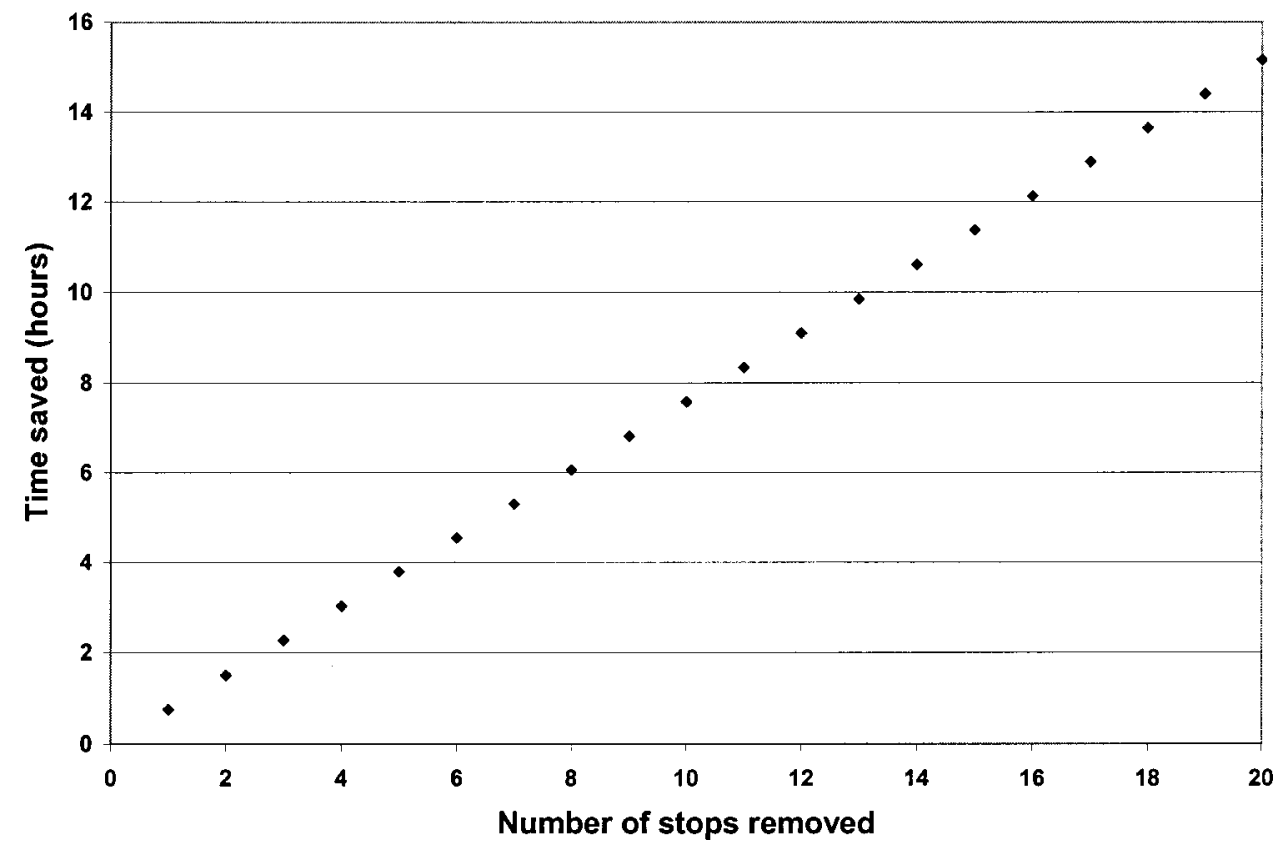

Fig. 16. Saving versus number of consolidated stops 


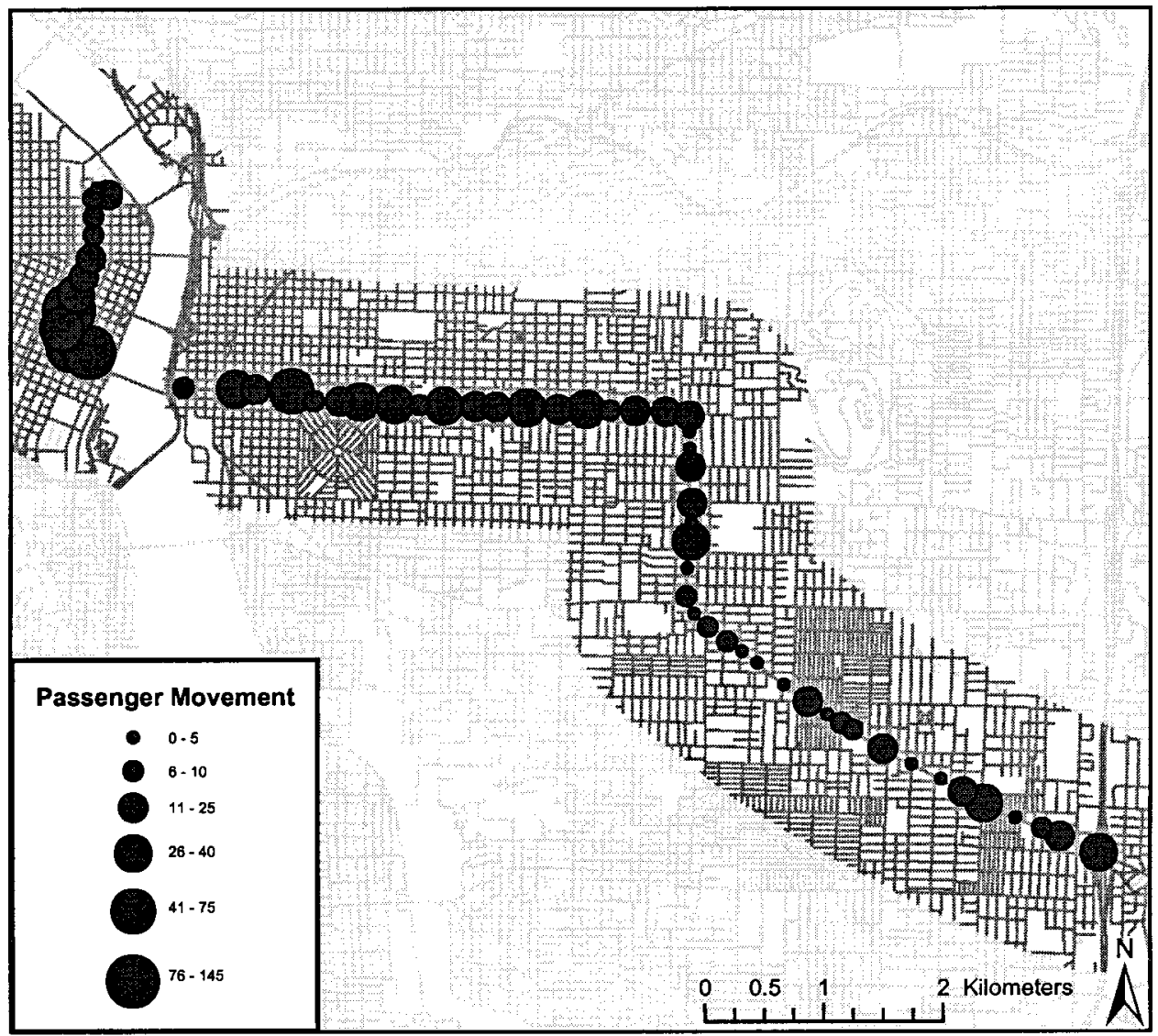

Projection: NAD 1983 StatePlane Oregon North FIPS 3601 Feet

Fig. 17. Location of high passenger movement on Route 14

a complete operational analysis, it is conceivable that this could result in the ability to add approximately ten additional trips to inbound Route 14 due to this change (assuming a similar strategy was applied in the outbound direction). This could result in reduced headways (the mean headway would drop from 11.4 to $10.4 \mathrm{~min}$ ) and improved service, in addition to shorter trip times. This would need to be balanced carefully against the additional walking/access distance for some passengers and the negative prospect of removing bus stops. Fig. 16 shows the relationship between the number of stops removed and the potential savings in time. Any stop consolidation decision would need to take into account existing passenger activity. Such data are available from the archived BDS data and should be evaluated to avoid any decrease in ridership.

The mean passenger boarding time has been estimated to be $3.6 \mathrm{~s}$. After observing passenger movement data, it is clear that there are some stops with higher passenger movement. An improvement in the boarding area configuration (e.g., by eliminating parking or constructing extensions to curbs) or in the ticketing system (e.g., increased use of passes, prepayment, electronic proximity cards, etc.) at these stops or throughout the system could reduce the mean time for passengers boarding the bus. On inbound Route 14, the four highest boarding locations in the study's sample are the following:

- Hawthorne Blvd. and SE 35th Ave.;

- Hawthorne Blvd. and SE 22nd Ave.;

- Hawthorne Blvd. and SE 19th Ave.; and

- Madison St. and SE 11th Ave.
Fig. 17 shows the stops with high passenger movement highlighted. At these stops, approximately 171 passengers boarded the bus during the period analyzed. If improved boarding areas and/or an improved ticketing system could reduce the mean passenger boarding time by $1 \mathrm{~s}$ (so the passengers boarding at these stops would need $2.6 \mathrm{~s}$ to board), it would save a total of 2.9 min during a 4 -h period. This could translate into about $57 \mathrm{~min} /$ day of service on Route 14.

Considering the stop consolidation and/or reduced boarding time concepts, the saving in time could be used to add service (increase frequency) or used as operational cost savings and improvement to the transit agency (Levinson 1983). On one hand, the agency could choose to add service in order to reduce the mean headway on a heavily used route like Route 14 . It is possible that the improved service and shorter trip times would lead to increased ridership and an associated increase in fare box revenue. On the other hand, if some bus stops were consolidated and boarding times reduced as described above, the transit agency could save a total of approximately $509 \mathrm{~min}(8.5 \mathrm{~h}) /$ day on inbound Route 14 alone. Assuming that it costs a transit agency on the order of $\$ 60 /$ vehicle hour to supply service, this would translate into about $\$ 509$ savings/day, or more than $\$ 180,000 /$ year for just this inbound route. When expanding this notion to both route directions and to the other 96 routes, it is clear that applying such improvements can have a substantial effect on the transit service and operation in the metropolitan area. Further research is needed to expand these concepts more holistically for this and other routes. 


\section{Conclusion}

As a result of this experiment it was shown that archived BDS data can be used to develop an innovative trip time model using just one transit route. This pilot study has produced a trip time model with statistically valid parameters that describe the transit trip in a reasonable way. One important finding was that the average nonstop speed was $30.3 \mathrm{~km} / \mathrm{h}(18.8 \mathrm{~m} / \mathrm{h})$, which indicates that the average speed can be no faster than this value unless changes are made to the roadway network and/or traffic signal control system (note that the "yield to bus" law is in effect in Oregon). In addition, the contribution of $26.0 \mathrm{~s} / \mathrm{stop}$ is substantial, and is increased $0.85 \mathrm{~s}$ for each alighting passenger and $3.6 \mathrm{~s}$ for each boarding passenger. This analysis provides firsthand evidence of the impact of the number of stops and the number of passengers in the estimate of total trip time. The analysis of dwell times provides useful results in terms of the mean time required for boarding and alighting.

The next steps will be to further validate and test this model for the same route using data from many days. Different models can be developed during the peak and off-peak periods to take into consideration the effect of congestion in the trip time model. The question of whether time of day should be used as a factor in estimating trip time will also be addressed in future studies. In addition, the city of Portland and TriMet have embarked upon a comprehensive program to install transit signal priority at key intersections throughout the city. It is possible that a trip time model similar to the one described here could be used to demonstrate and test the operational impact of traffic signal system improvements.

The most valuable aspect of this study was the ability to use the trip time model to test various strategies aimed at improving service and operation using a sensitivity analysis approach. A tool such as this trip time model can be a valuable component of a transit agency's operations planning process, and the technique described in this paper is especially useful since it is based on actual archived data from the BDS itself.

\section{Acknowledgments}

The writers would like to express their sincere gratitude to Steve Callas of TriMet for graciously providing the data used for analy- sis. In addition, they would like to thank James Strathman, Professor, and Thomas Kimpel, Research Associate, Center for Urban Studies, Portland State University, for their suggestions and helpful comments. Finally, they appreciate initial conversations with G. F. Newell and M. J. Cassidy of the University of California that prompted the development of the modeling approach described herein.

\section{References}

Chien, S. I., Chowdhury, S. M., Mouskos, K. C., and Ding, Y. (2000). "Enhancements of CORSIM model in simulating transit operations." J. Transp. Eng., 126(5), 396-404.

Kimpel, T. J. (2001). "Time point level analysis for transit service reliability and passenger demand." Special report, Center for Urban Studies, Portland State Univ., Portland, Ore.

Levinson, H. S. (1983). "Analyzing transit travel time performance." Transportation Research Record No. 915, Transportation Research Board, Washington, D.C., 1-6.

National Cooperative Highway Research Program (NCHRP). (1999). "Multimodal transportation: Development of a performance-based planning process." NCHRP Project No. 8-32(2), Cambridge Systematics, Inc., Oakland, Calif.

Newell, G. F. (1995). "Lecture notes on public transportation.” Dept. of Civil Engineering, University of California, Berkeley, Calif.

Saka, A. A. (2001). "Model for determining optimum bus-stop spacing in urban areas." J. Transp. Eng., 127(3), 195-199.

Strathman, J. G., Kimpel, T. J., and Dueker, K. J. (1999). “Automated bus dispatching, operations control and service reliability." Transportation Resesearch Record No. 1666, Transportation Research Board, Washington, D.C., 28-36.

Strathman, J. G., Kimpel, T. J., Dueker, K. J., Gerhart, R. L., Turner, K., Griffin, D., and Callas, S. (2001). "Bus transit operation control: Review and an experiment involving Tri-Met's automated bus dispatching system.” J. Public Transp., 4(1), 1-26.

Strathman, J. G., Kimpel, T. J., Dueker, K. J., Gerhart, R. L., Turner, K., Taylor, G., and Griffin, D. (2000). "Service reliability impacts of computer-aided dispatching and automatic vehicle location technology: A case Tri-Met case study." Transp. Q., 54(3), 85-102. 